\title{
De repente, aulas online: um relato de experiência docente no Ensino Superior em Direito durante a pandemia
}

\author{
Suddenly, online classes: a report of teaching experience in higher \\ education in law during the pandemic
}

De repente, clases virtuales: un informe de experiencia docente en educación superior en derecho durante la pandemia

Olívia de Quintana Figueiredo Pasqualeto ${ }^{1}$

https://orcid.org/0000-0001-5218-4954

Salete de Oliveira Domingos ${ }^{2}$

https://orcid.org/0000-0001-7054-567X

Vinícius Custódio Rios 3

https://orcid.org/0000-0002-0132-917X

Resumo: A pandemia de Covid-19 provocou reflexos inesperados nas mais diversas searas, dentre elas, a educação. Em um curto período, professores acostumados com a sala de aula presencial tiveram que se adaptar às aulas online. Considerando esse contexto, baseado em pesquisa bibliográfica e relato de experiência, este estudo objetiva relatar como se deu a nossa adaptação para as aulas online no Ensino Superior em Direito, analisando quais foram os principais desafios e as estratégias utilizadas para enfrentá-los. Verificamos inicialmente uma fase de transição, marcada pelo estranhamento às tecnologias, adaptação aos novos protocolos e à dinâmica

'Doutora e Mestra em Direito do Trabalho e da Seguridade Social pela Faculdade de Direito da Universidade de São Paulo. Pesquisadora da Escola Superior da Advocacia de São Paulo. Professora da Universidade Paulista. Professora da Universidade São Judas Tadeu. Professora na Escola de Direito de São Paulo da Fundação Getúlio Vargas. Pesquisadora sênior do Centro de Ensino e Pesquisa em Inovação da Fundação Getúlio Vargas. Atualmente realiza Pós-Doutorado com apoio do $\mathrm{CNPq}$ na Universidade de São Paulo. E-mail: oliviapasqualeto@hotmail.com

2 Doutora em Direito pela Pontifícia Universidade Católica de São Paulo. Docente da Universidade Paulista e da Universidade São Judas Tadeu. Atualmente realiza Pós-Doutorado na Pontifícia Universidade Católica de São Paulo. E-mail: saleteod@gmail.com

${ }^{33}$ Doutorando e Mestre em Direito pela Pontifícia Universidade Católica de São Paulo. Docente da Universidade Paulista e do Centro Universitário Estácio de São Paulo. E-mail: viniciuscrios@gmail.com 
virtual. Posteriormente, foi possível identificar desafios de longo prazo, como a pouca participação dos alunos, a dificuldade com as peculiaridades do tempo virtual e a adaptação às ferramentas tecnológicas. Por fim, foi possível identificar boas práticas para o ensino remoto, com destaque para o uso de metodologias ativas e criação de momentos de acolhimento dos estudantes.

Palavras-chave: Aulas online. Ensino Superior em Direito. Pandemia.

Abstract: The Covid-19 pandemic caused unexpected reflexes in the most diverse fields, including education. In a short period, teachers used to the day-to-day classroom experience had to adapt their routine to online classes. Considering this context, based on bibliographic research and case study this study aims to describe how our adaptation to online classes in Higher Education in Law took place, analyzing what were the main challenges and the strategies used to face them. We initially noticed a transition phase, marked by the lack of knowledge about technologies, adaptation to new protocols and virtual dynamics. Subsequently, it was possible to identify long-term challenges, such as poor student participation, difficulty with the peculiarities of virtual time and adaptation to technological tools. Finally, it was possible to identify good practices for remote teaching, with emphasis on the use of active methodologies and the creation of moments of welcoming students.

Keywords: Online classes. Higher Education in Law. Pandemia.

Resumen: La pandemia de Covid-19 causó reflejos inesperados en los más diversos campos, entre ellos, la educación. En poco tiempo, los profesores acostumbrados a las clases presenciales tuvieron que adaptarse a las clases online. Teniendo en cuenta este contexto, a partir de la investigación bibliográfica y el estudio de casos, este estudio tiene como objetivo describir cómo fue nuestra adaptación a las clases online, analizando cuáles fueron los principales retos y las estrategias empleadas para superarlos. Inicialmente notamos una fase de transición, marcada por el desconocimiento sobre tecnologías, adaptación a protocolos y dinámicas virtuales. Posteriormente, fue posible identificar desafíos a largo plazo, como la escasa participación de los estudiantes, la dificultad con el tiempo virtual y la adaptación a herramientas tecnológicas. Finalmente, fue posible identificar buenas prácticas para la enseñanza a distancia, con énfasis en el uso de metodologías activas y creación de momentos de acogida de estudiantes.

Palabras clave: Clases virtuales. Educación Superior en Derecho. Pandemia.

\section{Introdução}

O século XIX foi o século das novidades, das descobertas no tocante às ciências. As revoluções liberais e industriais foram determinantes para os avanços tecnológicos do século $X X$. $O$ advento da globalização, no final do século $X X$, deu início ao novo tempo, e, com a difusão da internet, a forma de pensar e agir foi substancialmente alterada, provocando drástica mudança comportamental que ocorreu em todo e qualquer seguimento no mundo. Desde o espaço de conflitos, no qual mesmo em meio ao campo bélico, a humanidade fez grandes descobertas, tal como a internet aqui citada, que surgiu do aprimoramento das técnicas de comunicação em meio às guerras, bem como nos relacionamentos humanos e, o que não poderia ser diferente, na educação.

No atual século $X X I$, achamos que estávamos vivendo uma revolução tecnológica em razão da inteligência artificial, dentre tantos outros acontecimentos tecnológicos que alteraram a forma de comunicação e de relacionamento entre as pessoas, alterando as formas de aprendizado. Muito já se falava em novas metodologias de aprendizagem, visto que a evolução da sociedade nos âmbitos social, econômico e tecnológico, denotam que a forma de aprender e ensinar seguindo essa métrica tem mudado. 
Todavia, nada se compara ao que começamos a experimentar especialmente a partir do mês de março de 2020, no Brasil, em razão do espraiamento da pandemia de Covid-19. Fomos forçados a viver um novo momento na educação. Da noite para o dia, professores, sem o preparo técnico ou emocional necessário, foram obrigados a ministrar aulas por plataformas digitais. Sem nenhum precedente, a pandemia mudou a forma da comunicação e de relacionamento, na educação não foi diferente, e é sobre estes aspectos que queremos desenvolver algumas reflexões a partir da nossa experiência.

Assim, baseada no método indutivo (MARCONI; LAKATOS, 2003) a partir de pesquisa bibliográfica (GIL, 2008) e da técnica do relato de experiência (DALTRO; FARIA, 20I9), este texto tem como objetivo descrever como ocorreu a nossa adaptação do ambiente presencial para o ambiente virtual, analisando quais foram os principais desafios e as estratégias utilizadas para superálos ou, ao menos, minimizá-los.

Os resultados encontrados em nossa pesquisa são apresentados neste texto, organizado em três grandes partes: relato sobre a primeira semana de transição e adaptação repentina ao ambiente virtual; sistematização dos desafios verificados nas aulas remotas; identificação de boas práticas para enfrentar as dificuldades postas. Por fim, são apontadas considerações finais sobre a nossa percepção diante do cenário de ensino remoto no ensino superior em direito durante a pandemia de Covid-19.

\section{Do ambiente presencial para o virtual - a primeira semana de transição e adaptação}

São Paulo, sexta-feira, 13 de março de 2020. Neste dia, recebemos a notícia que, a partir de então, as aulas presenciais teriam que ser interrompidas em razão da pandemia. Nossa primeira reação envolveu dezenas de questionamentos: desde os mais simples - "como vai ser?", "vamos dar aula online?", "e se a minha internet falhar?", "será que os alunos vão conseguir acessar?" - até os mais complexos: "como tranquilizar os alunos?", “como será a avaliação desses estudantes?”. A primeira semana de aulas online pode ser considerada uma semana de transição, já que foi necessário nos adaptarmos a uma realidade completamente nova, ainda marcada por algumas incertezas e experimentações.

Nesta primeira semana, pudemos conhecer e testar diferentes plataformas online para viabilizar as aulas (tais como o Zoom, Google Meets, Microsoft Teams, Youtube, etc.). O primeiro obstáculo foi se ambientar tecnologicamente nas plataformas e eleger uma delas para seguir adiante, considerando a facilidade do docente e dos alunos em ingressar em cada plataforma.

A segunda adaptação necessária evidenciada nessa primeira semana envolveu as novas diretrizes provenientes das instituições de ensino. A fim de proporcionar mais segurança aos alunos e docentes, bem como adequar-se jurídica e tecnicamente às exigências do Ministério da Educação, as 
De repente, aulas online: um relato de experiência docente no Ensino Superior em Direito...

instituições de ensino criaram uma série de novos protocolos a serem seguidos, tais como o preenchimento de formulários, formas de comunicação com os alunos, etc. Muitos, como nós, que são docentes de mais de uma instituição tiveram que se adequar às diretrizes específicas de cada uma delas. Assim, foi necessário adaptar-se aos novos procedimentos de formalização das atividades desenvolvidas.

Para além das adaptações acima, que podem ser consideradas como adaptações de infraestrutura, citamos também as adaptações no processo de ensino-aprendizagem propriamente. Nesse sentido, especialmente nesta primeira semana, fomos desafiados a acolher os alunos e suas angústias sobre o cenário atual e sobre o futuro profissional, bem como a adequar nossas aulas ao tempo, ritmo e espaço virtual.

\section{Do ambiente presencial para o virtual - identificação dos desafios}

O ensino jurídico, assim como de qualquer outra ciência, bem como a própria sociedade, perfez uma longa trajetória de evolução. Os dois primeiros cursos jurídicos no Brasil foram criados por D. Pedro I, em 1827, e, desde então, o ensino jurídico é historicamente aplicado da mesma forma: sala de aula com as carteiras enfileiradas, uma lousa na frente da sala, alunos observando a aula expositiva do professor sobre uma disciplina departamentalizada (GHIRARDI, 20I7), que é (ou era) tradicionalmente o detentor e fonte do conhecimento ou saber jurídico (RAMOS; SCHORSCHER, 2009).

Essa forma de ministração de aulas - que, lenta e gradativamente, vem dividindo espaço com o emprego de metodologias ativas - tende a não dialogar com o educando, que permanece em uma posição passiva de ouvinte da aula e receptor de conteúdo, afastando-o da participação mais ativa do processo de ensino-aprendizagem. Tal modelo tradicional do ensino jurídico em que o aluno é sujeito passivo na aprendizagem ficou ainda mais evidente no ambiente virtual, já que em muitas salas de aula, demos aula sem poder ver o rosto dos alunos - já que muitos não possuíam ou não se sentiam confortáveis em ligar as suas câmeras - e sem receber o retorno por parte deles - já que muitos não se manifestavam pelo microfone e nem pelo campo "bate-papo" existente nos aplicativos. Nesse sentido, um dos maiores desafios dessa transição foi a tendência ao monólogo do professor (ministrando aulas para a tela de um computador).

A pouca participação dos alunos, especialmente na fase de transição, evidenciou que a aula online acabava por render mais, restando mais tempo para que o professor aprofundasse o conteúdo a ser transmitido. No entanto, embora tivéssemos mais tempo para dissertar sobre o conteúdo programático, notamos que as aulas poderiam se tornar mais densas, cansativas e desestimuladoras para os alunos e para os docentes. Vale notar, contudo, que a questão da participação dos alunos não 
foi homogênea, pois, ao passo que percebemos, especialmente no início, a diminuta participação (poucas perguntas, reflexões e dúvidas), sentimos também que alguns alunos acabaram por vencer a timidez ao utilizar a ferramenta "bate-papo". Como não era necessário falar em público, alguns alunos comentaram que assim se sentiam mais confortáveis em participar. Com isso, com o avanço das semanas e das aulas online, começamos a notar que alguns alunos começaram a interagir conosco.

Outro desafio vivenciado diz respeito à dificuldade em perceber se os alunos estão realmente compreendendo a aula e se há dúvidas. Como comentado, por diferentes motivos, a grande maioria dos discentes não permanecem com a câmera ligada durante a aula. Assim, sentimos que a perda na percepção advinda interação visual e da linguagem corporal é um obstáculo a ser transposto.

Por fim, destacamos o desafio de se adequar às novas tecnologias que passaram a fazer parte do nosso dia-a-dia. Muitos professores se ajustaram facilmente, mas percebemos que muitos colegas tiveram dificuldades em se adaptar às novas tecnologias, havendo certo estranhamento com as novas ferramentas (a exemplo dos formulários online, aplicativo para reuniões online, etc.). Esse desajuste entre competências pessoais e novas tecnologias (OIT, 2019) foi observado não só em relação aos docentes, mas também em relação aos discentes: muitos alunos comentaram sobre a dificuldade em se familiarizar com a tecnologia utilizada, bem como em acessar a internet por falta de infraestrutura adequada.

Identificados - intuitiva ou sistematicamente - os desafios, tentamos adotar algumas estratégias para superá-los. A conversa com os nossos pares e o treinamento conjunto (fornecido pelas instituições de ensino e/ou organizado pelos próprios docentes), nesse momento, foi essencial para compartilhar as novas dificuldades e pensar, de forma colaborativa, quais instrumentos poderiam ser testados a fim de melhorar o processo de ensino-aprendizagem durante a pandemia e, também, depois dela.

\section{Do ambiente presencial para o virtual - evolução e boas práticas}

Passada a primeira semana de transição, podemos perceber alguns pontos a serem melhorados e outros a serem mantidos. Assim, identificamos algumas boas-práticas utilizadas que nos permitiram evoluir pouco a pouco nesse processo.

A primeira boa prática constatada corresponde à designação de um tempo da aula ou de alguma das aulas para uma conversa mais informal com os alunos. Notamos que momentos de acolhimento e de escuta foram fundamentais para que os alunos se sentissem mais seguros e determinados a continuarem os seus estudos mesmo em um momento de incerteza, como este originado pela pandemia. Durante essas conversas, percebemos que muitos alunos estão ansiosos e com diferentes dificuldades pessoais (financeiras e familiares). Assim, sentimos que dar espaço para que compartilhem 
De repente, aulas online: um relato de experiência docente no Ensino Superior em Direito...

suas angústias foi importante para estreitar os laços entre discente e docente e, consequentemente, entre discente e instituição de ensino. Nesse sentido, ressaltamos iniciativas como a realização de um café virtual conjunto durante o intervalo, a escuta de músicas no início ou fim da aula, etc.

A segunda boa prática identificada foi a utilização de ferramentas tecnológicas que favorecem a interação durante a aula e atraem participação dos alunos. Destacamos ferramentas que permitem a criação de jogos virtuais (a exemplo do aplicativo Kahoot) e a ferramenta Mentimeter, por meio da qual é possível fazer perguntas a serem respondidas de forma anônima e simultânea pelos alunos, enquanto a ferramenta apresenta os resultados ao professor, que pode compartilhá-los na tela com toda a sala. Em um dos usos dessa ferramenta, perguntamos aos alunos qual palavra poderia ser usada para definir a sua expectativa em um mundo pós-pandemia. No formato "nuvem de palavras", recebemos as respostas abaixo:

Figura I: Nuvem de palavras sobre a expectativa dos alunos para o pós-pandemia, 2020.

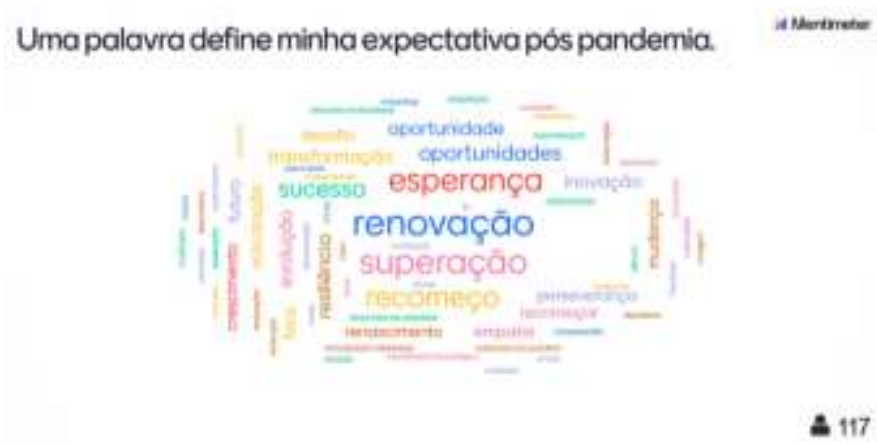

Fonte: Elaboração dos autores, 2020.

O resultado chamou a atenção de todos, visto que muitos esperam que o mundo pós-pandemia seja preenchido de esperança, renovação e superação.

A terceira boa prática identificada foi a realização de exercícios durante a aula. Como comentado, o ensino jurídico tradicional está comumente baseado em aulas expositivas. Percebeu-se que o emprego de outras metodologias de ensino foi essencial para tornar as aulas mais interessantes para os alunos. Assim, buscamos aplicar exercícios para que os alunos refletissem individual e coletivamente sobre a aplicação prática da teoria, intercalando diferentes atividades durante a aula.

A quarta boa prática identificada corresponde ao ensino do direito por meio de situações concretas - substituindo práticas pedagógicas pouco atrativas e incapazes de eliminar o "descompasso entre o Direito ensinado e o Direito vivido" (BADIN; GIANNATTASIO; CASTRO, 20I7, p. 2) - e/ou a partir de filmes, fotografias, poemas e/ou músicas, capazes de estimular a reflexão por parte dos alunos. Sentimos que, ao colocar o discente em uma situação em que ele necessita articular teoria e 
prática, tornou a aula mais participativa e dialogada, além de estimular um pensamento complexo, pautado na interdisciplinaridade e conexão do direito com outras searas.

Nesse sentido, trazemos o discente para o centro da construção do conhecimento, tornandoo um sujeito mais ativo no processo de ensino aprendizagem, enquanto o educador passa da figura de detentor do conhecimento para a figura de mediador na construção do conhecimento de forma interdisciplinar.

Por fim, salientamos a importância de manter um canal aberto com os alunos, durante a aula (com a permissão de ligarem o microfone e a câmera, bem como de utilizar o "bate-papo") e fora dela, por meio de e-mails ou outros canais de comunicação institucional. Sentimos que essa conversa aberta foi essencial para aparar arestas, superar eventuais falhas de comunicação e nos apoiarmos nesse processo de ensino-aprendizagem neste momento.

\section{Considerações finais}

Buscamos, neste texto, refletir sobre as nossas experiências durante a transição da sala de aula presencial para a virtual no curso de direito durante a pandemia de Covid-19, que evidenciou a necessidade de o ensino do direito ir além das aulas expositivas convencionais, sendo necessário uma metodologia que se mostre mais atraente, pois é importante pensar o curso de Direito sob o prisma da formação integral do educando, despertando nele o senso crítico, os valores éticos e propiciar o desenvolvimento do senso de justiça para aplicação do Direito na vida prática de maneira mais humanizada, e, não meramente tecnicista.

É sabido que a sala de aula - seja ela presencial, seja ela virtual - se configura em espaço propício para que o docente crie novos métodos que possam atrair a atenção do educando e melhor preparálo para desenvolver o conhecimento acadêmico. Não afirmamos que as plataformas substituem o convívio da sala de aula, mas que estímulos novos foram ofertados.

Nesse sentido, enquanto estivermos nesse ambiente virtual, entendemos necessário utiliza-lo de forma a construir conjuntamente um processo de ensino-aprendizagem que seja mais participativo, interdisciplinar e plural. Entendemos que, nesse processo, discentes e docentes precisarão se adaptar e se esforçar para que haja frutos. Quanto ao nosso papel, como professores, acreditamos que a capacitação contínua, a abertura para testar novas metodologias e o diálogo entre nós mesmos e com os discentes são pilares fundamentais para que a educação no mundo pandêmico - e pós-pandêmico possa florescer. 


\section{Referências}

BADIN, M. R. S.; GIANNATTASIO, A. R. C.; CASTRO, D. O caso didático no ensino do direito internacional: um instrumento para um aprendizado interdisciplinar com relações internacionais. Meridiano 47 Journal of Global Studies. Brasília, v. 18, p. I-17, 2017.

DALTRO, M. R.; FARIA, A. A. Relato de experiência: uma narrativa científica na pósmodernidade. Estudos e Pesquisas em Psicologia, Rio de Janeiro, v. 19, n. I, p. 223-237, 2019.

GHIRARDI, J. G. Ensino do direito. Enciclopédia Jurídica da PUCSP. Tomo Teoria Geral e Filosofia do Direito. I. ed. 2017.

GIL, A. C. Métodos e técnicas de pesquisa social. 6. ed. São Paulo: Editora Atlas SA, 2008.

MARCONI, M. A.; LAKATOS, E. M. Metodologia científica. 5. ed. São Paulo: Atlas, 2003.

OIT. Skills and jobs mismatches in low - and middle - income countries. Genebra: International Labour Office, 2019.

RAMOS, L.; SCHORSCHER, V. O Método do Caso. In: GHIRARDI, J. G. Métodos do ensino em direito. São Paulo: Saraiva, 2009.

Recebido em: 15 de junho de 2020.

Versão corrigida recebida em: 26 de outubro de 2020.

Aceito em: 18 de novembro de 2020.

Publicado online em: 08 de maio de 2021 . 